\title{
Concerning public health situation of under-nutrition in children and anemia in women in Indian Sundarbans delta: a community based cross-sectional investigation
}

Samiran Panda ${ }^{1 *}$, Chittapriyo Sadhu², Gopal Pramanik ${ }^{3}$, Sobha Pahari ${ }^{4}$ and Jakir Hossain ${ }^{4}$

\begin{abstract}
Background: The National Family Health Survey-Round 3 in India during 2005-2006 recorded more children and women as anaemic compared to the prevailing situation eight years ago; more children also had wasting. Analysis of this dataset further linked adversity, rather than intrauterine biological processes, with under-nutrition running across generations. Against this background we conducted the present situation assessment in the Sundarbans area of India. The Sundarbans is world's largest delta with mangrove forest and prone to natural disasters.

Methods: The current community based investigation was undertaken in five villages under Patharpratima block of the Sundarbans. Participants were selected randomly from the lists of eligible children (aged $\leq 5$ year) and married women ( $\leq 49$ year) prepared for each of the villages. Interviewer administered questionnaire, tools for anthropometry and hematologic auto-analyzer were used. Data from 561 children and 1145 married women (of which 55 were pregnant) were analysed.

Results: Underweight and stunting were recorded in 40 and $51 \%$ of the children respectively. Of the 561 children, 47 (8\%), had severe acute malnutrition. Weight for height z-score reflecting acute and chronic state of nutritional deprivation revealed that four of the five villages were in critical stage. One fourth of the women had low body-massindex (BMI). Hygienic practices of women were also poor; $41 \%$ reportedly used water, mud/ash and not soap to wash hands after defecation. Anaemia prevalence in women of all the villages was $>40 \%$ underscoring a sever public health situation. Factors independently associated with anaemia in non-pregnant women (698/1090; 64 \%) were residentialvillage, low (<18.5 kg/m2) BMl of women (Adjusted Odds Ratio; AOR =1.39; 95 \% Cl of AOR 1.02-1.89), non-adoption of family planning method (AOR 1.86; $95 \% \mathrm{Cl}$ of AOR 1.36-2.54; $p<0.001$ ) and adopting contraceptive practices other than oral pills (AOR 1.84; $95 \%$ Cl of AOR 1.32-2.56; $p<0.001$ ).

Conclusions: Sundarbans poses its unique public health challenge due to geographical-vulnerability. Securing nutritional support emerges as an immediate need for the study population residing in this natural-disaster prone area of islands and estuaries. The existing situation of anaemia in women requires innovative intervention development and would require addressing health seeking practices. Behavioural intervention appears to be the key.
\end{abstract}

Keywords: Under-nutrition, Breast feeding, Anemia, Women, Geographical vulnerability \& health

\footnotetext{
* Correspondence: pandasamiran@gmail.com

${ }^{1}$ National Institute of Cholera \& Enteric Diseases (NICED, Indian Council of

Medical Research), P-33 CIT Road, Scheme-XM, Beliaghata, Kolkata PIN -

700010, West Bengal, India

Full list of author information is available at the end of the article
} 


\section{Background}

Analysis of maternal and child health in South Asia in early 2000 underscored the importance of health system strategies to improve the existing situation [1]. A relatively recent comparative study revealed that in the area of child survival, India lagged behind [2] other south and south-east Asian countries such as Nepal, Bangladesh and Indonesia. Contrasting the National Family Health Survey (NFHS Round 3) findings of 2005-2006 with that of an earlier survey, the study even highlighted that more children and women in India had anemia than in 1998 and more children showed wasting through malnutrition. A different team of researchers, who also used the NFHS 2005-2006 dataset, concluded that intergenerational mechanisms linking under-nutrition across subsequent generations seemed to depend particularly on continuity of adversity, rather than being determined by intrauterine biological processes [3]. Against this background, the current study was situated in the Sundarbans area of the district of south-24 Parganas in West Bengal, India. The overall purpose was to assess the situation of under-nutrition of children and anemia in women so that the government officials, civil society organizations and local communities could be appropriately informed and engaged in development of remedial measures.

Sundarbans, the largest delta of the world near bay of Bengal is a world heritage site, covers an area of $9630 \mathrm{~km}^{2}$ and is divided between Bangladesh and India. The area is prone to natural calamities. The Indian part of Sundarbans is smaller, covers $19 \%$ of the total area and has a population of 4.5 million. It is situated $125 \mathrm{kms}$ southeast to Kolkata, the capital city of West Bengal. Developmental challenges in the Sundarbans include but not restricted to low agricultural yield due to high soil salinity and ecological vulnerability from unpredictable climatic conditions [4]. Majority of the inhabitants depend on agriculture and face the challenge of considerable amount of land being engulfed by the rising sea level every year.

The present community based investigation was undertaken during 2012-2013 in the Patharpratima block of the Sundarbans (blocks represent planning and development units of a district). As the area was devastated along with other coastal districts of West Bengal following tropical cyclone AILA in 2009 [5, 6], the current investigation assumed importance from the larger perspective of changing environment and health vulnerability. We obtained approval of the scientific and institutional ethics committees of the National Institute of Cholera \& Enteric Diseases (NICED), a premier institute of Indian Council of Medical Research (ICMR) located in Kolkata, prior to initiation of recruitment of the study participants.

\section{Methods}

Study area

The Patharpratima block has 92 villages of which five were included in the current study. The three villages namely Durbachati, Ramganga and Gopalnagar (DC-RGGN), being the field area of partnering civil society organization 'Sundarban Social Development Centre' (SSDC), were under the purview of the present health assessment. The two other villages namely Dakshinraypur (DR) and Sreenarayanpur Purnachandrapur (SNP), which were covered as comparators, were in close proximity to DC-RG-GN and did not have SSDC-presence. Projects carried out by SSDC at different points in time in DC-RG-GN were on 'nutrition,' 'water, sanitation and hygiene' (WASH) and 'issues around rights of children and women'. The current assessment provided an opportunity to examine if situations of health of women and children in villages with SSDC-presence were better than that in comparator villages. An upcoming initiative of SSDC aiming to reduce vulnerability to environment induced health hazards among women and children in the Sundarbans necessitated the current investigation as a pre-requisite.

\section{Participants}

Participants were selected randomly from the lists of eligible children (aged $\leq 5$ year) and married women ( $\leq 49$ year) prepared for each of the study villages. Informed consent was obtained from every participant before recruitment in the study. Guardians (mostly mothers) provided consent for participation of children. Data from 561 children and 1145 married women were used in analyses. Twelve of 561 families (2\%), participating in assessment of children, were common and became part of the assessment of women's health as well. Random draw of the study participants from master lists resulted in such commonality. Based on earlier investigations, we expected $40 \%$ 'under-weight for age' in children [7] and $25 \%$ anaemia in women [8]. Sample sizes were calculated with $90 \%$ confidence level and $8 \%$ relative precision. Practicalities such as available resource (time and money) and feasibility of covering larger sample size calculated with relatively stringent assumptions (such as $95 \%$ confidence and $5 \%$ relative precision) guided us to follow less rigorous assumptions as discussed by Lwanga and Lemeshaw [9]. Based on the aforementioned considerations, required sample size for children was 634 and for women 1268. Number of the participants covered in analyses were less than the calculated sample sizes, mostly due to non-availability of identified individuals at their respective residences during survey visits and a few incomplete interviews. The difficult study terrain did not allow paying more than two visits for any defaulter in recruitment. 


\section{Study tools}

The tools used in the present structured crosssectional survey included interviewer administered questionnaire, instruments for anthropometric measurements and hematologic auto-analyzer. Women were interviewed one-on-one. The domains of inquiry, among other things, constituted socio-demographic profile, types of food consumed, general health issues, sources of drinking water used, handling of drinking water at home, water used for washing utensils and reproductive health. In order to create a composite score for 'Standard of Living Index' (SLI), we inquired also about ownership of house and house type, possession of agricultural land, presence of livestock, assets related to transportation (bicycle, bullock cart, moped etc.), goods for entertainment and communication (such as radio, television), toilet facilities used, access to electricity, sources of water used, fuel type used for cooking etcetera. Composite SLI-scores ranging from 0 to 14 were considered low, $15-24$ as medium and 2567 as high for a family [10]. The tool used to create SLI-score for the families either participating in assessment of health of women and/or of children was the same. The difference in socio-economic conditions encountered in women and children could thus be attributed to random draw of samples from two different master lists. Each child was subject to anthropometric measurements and information on their vaccination details were also collected.

\section{Nutritional assessment in children}

Nutritional assessment of children $\leq 24$ months of age was carried out by measuring weights and lengths. Infantometer was used to measure length of these children in supine posture. For children $>24$ months of age, anthropometer rod was used for measuring height in standing position. Weight for age $\mathrm{z}$-score, weight for height z-score and height for age z-scores were calculated to identify children with underweight, wasting and stunting respectively. Mid- upper arm circumference (MUAC) was measured at the midpoint of the distance between acromian process of scapula and olecranon process of ulnar bone of the left arm [11].

Estimated percentage of children belonging to ' $<-2$ weight for height (WfH) z-score' group helped classifying study-villages in different categories in terms of wasting (reflects both acute as well as chronic form of under-nutrition) as suggested by the World Health Organization (WHO). According to WHO-criteria [12], $<5 \%$ children belonging to ' $<-2$ weight for height (WfH) z-score' group indicates acceptable, 5$9.9 \%$ poor, $10-14.9 \%$ serious and $>15 \%$, critical situation of under-nutrition.
Body mass index (BMI) and measurement of hemoglobin in women

Women were assessed for height and weight by anthropometer rod and digital weighing scale respectively. Accuracy of the weighing machines were checked regularly against standard weights made available by bureau of standards, government of India. Women with low BMI were identified by using WHO cut-off (below $18.5 \mathrm{~kg} / \mathrm{m}^{2}$ ) for Asian population [13]. Haemoglobin (Hb) estimation was carried out by using three part auto hematologic analyzer. The cut-off value used to define anaemia in non-pregnant women (aged $\geq 15$ year) was Hb-level $<120 \mathrm{~g} / \mathrm{l}$. As anaemia in pregnant women is defined at a lower haemoglobin level cut-off $(<110 \mathrm{~g} / \mathrm{l})$, we have presented the data accordingly. Villages were classified depending on the prevailing situation of anaemia ( $<4.9 \%$ prevalence indicating no public health problem, $5-19.9 \%$ mild, $20-39.9 \%$ moderate and $\geq 40 \%$ prevalence indicating severe) [14].

\section{Analyses}

Applying WHO standards (WfH $\mathrm{z}<-3$ ) as well as MUAC cut-off of $115 \mathrm{~mm}$, we estimated the number of children with severe acute malnutrition (SAM). Both the criteria were applied as cases selected using weight-forheight $\mathrm{z}$-score and MUAC are not the same [11]. Estimated percentage of children in two groups; one with a) $\mathrm{z}$-score $<-3 \mathrm{SD}$ and $\mathrm{b}) \mathrm{z}$-score $<-2 \mathrm{SD}$ have been generated for descriptive statistics on underweight, wasting and stunting reflected through weight for age z-score (WfAz), weight for height z-score (wfhz) and height for age $\mathrm{z}$-score (HfAz) respectively.

Blood specimen was collected from each of the consenting women for $\mathrm{Hb}$-level estimation. Non-pregnant women with $\mathrm{Hb}$-level $<120 \mathrm{~g} / \mathrm{l}$ were grouped as cases and the rest as comparators. Exposure variables tested for their association with the study outcome (presence of anaemia indicated by $\mathrm{Hb}$-level $<120 \mathrm{~g} / \mathrm{l}$ ) were selected a priori. Information on exposures were collected through interviewer administered questionnaire. Key exposures (explanatory variables), among other things, comprised of education, contraceptive practices, number of offspring, dietary habits and different hygienic and sanitary practices. Association of each of these exposure variables with anaemia, the binary outcome variable of interest, was examined through uni-variate analyses. Variables showing significant statistical association $(p<0.05$ and confidence interval of odds ratios not capturing the null value of 1 ) with anaemia in uni-variate analyses and having conceptual relevance to intervention development along with biologic plausibility were entered simultaneously in a multivariate logistic regression model and adjusted for potential confounders such as 'age' and 'residential-village'. 
Analysis for determinants of anaemia in pregnant women could not be conducted due to low number of participants in this group. Software packages Epi-Info (version 6.4b, Centres for Disease Control, Atlanta, GA, in collaboration with World Health Organization, Geneva, Switzerland), WHO Anthropo (version 3.2.2) and SPSS (version 8.0 SPSS, Chicago, IL) were used for data analyses.

\section{Results}

\section{Socio- demographic profile}

Fifty four percent of the children surveyed were male (304/561); by faith most of the families they belonged to were Hindu (491/561; $87 \%$ ) and the rest Muslim. Thirty eight children $(7 \%)$ were below six month of age and the rest were within 6 to 60 month age bracket. While 196 children participated from DC-RG-GN (35\%), 180 were from DR (32 \%) and 185 (33 \%) were from SN. As per composite SLI score, a fifth of the children surveyed from DC-RG-GN belonged to low socio-economic strata and very few children in DR (14/180; $8 \%)$ and SN (10/ $185 ; 5 \%)$ were in this group. Overall, $12 \%(66 / 561)$ of the children were in low, $57 \%(319 / 561)$ in medium and $31 \%(176 / 561)$ in high socio-economic group.

Of the 1145 married women recruited in the current survey, 55 were reportedly pregnant. The following results relate to 1090 non-pregnant women, about a third of whom, belonged to each of the three types of study villages (DC-RG-GN, DR and SNP). The mean age of the women was 29 year (median 27; $\mathrm{SD} \pm 8$; minimum 15; maximum 49). According to composite SLI score, $54 \%(586 / 1090)$ belonged to families in low socioeconomic category, $38 \%(417 / 1090)$ in the middle and $8 \%(87 / 1090)$ in higher bracket. While only $6 \%$ of women were engaged in income generation activities, $93 \%(1017 / 1090)$ reported their spouses being the bread winner of the families; Table 1 presents additional sociodemographic information.

\section{Nutritional status of children \& related issues}

While severe underweight (WfA z-score $<-3$ ) and severe stunting (WfH z-score $<-3$ ) were observed in $14 \%$ and $31 \%$ of children respectively, overall prevalence of underweight and stunting (indicated by respective $\mathrm{z}$ scores $<-2$ ) were 40 and $51 \%$. Categorization of villages based on prevalent situation of wasting, reflecting under-nutrition of both short and long duration, placed SNP in 'serious' $(22 / 185 ; 12 \%)$ and the rest of the villages in 'critical' zone of concern (DR 38/180; $21 \%$ and DC-RG-GN 51/196; $26 \%$ ). Of the 561 children, 47 $(8 \%)$, were diagnosed with SAM.

Forty six percent of the surveyed children reportedly were born at home and the rest experienced institutional delivery. Breast feeding was initiated by 70 \% (393/561)
Table 1 Socio-demographic profile of non-pregnant women participants

\begin{tabular}{|c|c|c|}
\hline Attributes & $\begin{array}{l}\text { Number } \\
(n=1090)\end{array}$ & $\begin{array}{l}\text { Percentage } \\
(\%)\end{array}$ \\
\hline Age $>34$ years & 288 & 26 \\
\hline$>29 \& \leq 34$ years & 172 & 16 \\
\hline$>24 \& \leq 29$ years & 221 & 20 \\
\hline$>19 \& \leq 24$ years & 331 & 31 \\
\hline$\leq 19$ years & 78 & 7 \\
\hline $\begin{array}{l}\text { Durbachati + Ramganga + Gopalnagar } \\
\text { (villages) }\end{array}$ & 403 & 37 \\
\hline Daskhinraypur (village) & 361 & 33 \\
\hline $\begin{array}{l}\text { Sreenarayanpur Purnachandrapur } \\
\text { (village) }\end{array}$ & 326 & 30 \\
\hline Hindu & 996 & 91 \\
\hline Muslim & 94 & 9 \\
\hline Ever attended school & 832 & 76 \\
\hline Never attended school & 258 & 24 \\
\hline Husband Ever attended school & 917 & 84 \\
\hline Never attended school & 173 & 16 \\
\hline Earns money & 62 & 6 \\
\hline Does not earn money & 1028 & 94 \\
\hline Husband earns money & 1017 & 93 \\
\hline Husband does not earn money & 73 & 7 \\
\hline Stays with husband & 1045 & 96 \\
\hline Does not stay with husband & 45 & 4 \\
\hline $\begin{array}{l}\text { Husband stays outstation due } \\
\text { to occupation }\end{array}$ & 28 & 62 \\
\hline $\begin{array}{l}\text { Husband stays outstation due } \\
\text { to other reasons }\end{array}$ & 17 & 38 \\
\hline Number of children $>2$ & 407 & 37 \\
\hline Number of children $\leq 2$ & 683 & 63 \\
\hline
\end{tabular}

of the mothers within an hour and $15 \%$ within $6 \mathrm{~h}$ of child birth. The rest reported initiating breast feeding within a day or even later after delivery. Colostrum was fed to newborn children by $89 \%$ of the mothers. In response to the question 'how many days did you feed your child with only breast milk', 6 of the 561 respondents $(1 \%)$ reported not breast feeding their children at all and $113(20 \%)$ reported exclusive breast feeding for less than six months. About a fifth of the mothers reported feeding water (plain water, anis water, honey water or sugar candy water as part of ritualistic practice) to newborn who were supposed to have breast milk only.

'Full immunization' is defined under the national immunization program in India as administration of Bacillus of Calmette-Guerin (BCG), three doses of oral polio vaccine, three doses of diphtheria-pertussistetanus (DPT) injection and measles vaccine to $12-23$ 
month old children. In our study cohort 119 children belonged to the age group of 12 to 23 month. Ninety two of such 119 (78 \%) children were estimated to be fully immunized.

\section{Hygienic practices}

Sources of drinking water, types of toilets used, water used in utensil washing, and hand washing practices after defecation were explored as indicators of hygiene. While $99.5 \%$ of non-pregnant women $(1085 / 1090)$ used tube-well (hand pump) water, only one reported using pond water and the rest few used pipe-water supply for drinking purpose. Eighty percent of the women reported washing utensils with pond water. While open defecation was reported by $13 \%$ (147/1090), pond-side latrine (a covered space for defecation where faecal contamination of environment takes place as in open defecation) reportedly was used by $7 \%$ (78/1090) and about one third of the respondents used pit latrine (376/ 1090). Forty three percent women $(465 / 1090)$ said that they were using sanitary latrine. Forty one percent women (437/1090) reported not using soap to wash hands after defecation; they rather used water, soil, ash etcetera. Distributions of these and other key exposure variables in women with anaemia and those who were not anaemic have been detailed in Table 2 .

\section{Health of women}

Sixty percent pregnant $(33 / 55)$ and $64 \%$ nonpregnant women $(698 / 1090)$ were anaemic; $24 \%$ $(266 / 1090)$ of the non-pregnant women had lower than normal BMI. One fourth of the non-pregnant anaemic women had hypochromic microcytic red blood cells (mean corpuscular volume $<81 \mathrm{fl}$ ) indicating a probable state of iron deficiency.

Association between key risk factors and anaemia in non-pregnant women were examined (Table 2). Religious affiliation, involvement of women in income generation activities, self-reported dietary habits (barring intake of germinated gram, which is a rich source of vitamin B12 \& folic acid), handling of drinking water at home, utensil wash practice, open air defecation and hand wash practice following defecation were not associated with anaemia. Factors independently associated with anaemia in non-pregnant women in multivariate model were identified after adjusting for age, residentialvillage, school attendance, number of offspring born to a woman, BMI, frequency of intake of germinated gram and contraceptive practice (Table 3). While women residing in DC-RG-GN had about 1.5 times the odds (adjusted OR 1.42; $95 \%$ CI of adjusted OR $1.01-2.01 ; p<$ 0.042 ) of having anaemia compared to women in SNP, women with $\mathrm{BMI}<18.5 \mathrm{~kg} / \mathrm{m}^{2}$ had similar odds of being anaemic. Also women currently not practising any family planning method (adjusted OR 1.86; $95 \%$ CI of adjusted OR $1.36-2.54 ; p<0.001$ ) or using contraceptive methods other than oral pills for family planning had about twice the odds of being anaemic compared to those using oral hormonal contraceptive pills (adjusted OR 1.84; 95 \% CI of adjusted OR 1.32-2.56; $p<0.001$ ).

\section{Discussion}

The current investigation reveals a concerning situation of under-nutrition in children and anemia in women in the Sundarbans area of West Bengal. Findings emerging from this study have implications for intervention development. However effective health service delivery in the natural-disaster prone geographical locations of Sundarbans crisscrossed by estuaries and islands in the Bay of Bengal is a public health challenge and effective engagement of local communities in intervention development is paramount. The poor state of healthcare infrastructure in Sundarbans has been highlighted in earlier investigations by researchers [15]. Worth noting in this context is that the present situation assessment was located in the Patharpratima block, one of the six blocks recorded to have relatively better healthcare facilities compared to others [16].

Eight percent of children in the present survey had SAM. Prevalence of wasting in four of the five studyvillages was assessed to be 'critical' - affecting one fifth of the surveyed population. In this context, it is important to note that of 19 million severe acute malnourished children in all developing countries, 8 million (42\%) are in India. This number constitutes one-third of the global burden $[17,18]$.

It is important to note from the perspective of intervention development that about $90 \%$ of SAM children do not present with medical complications and can be cared for in their communities without admitting them to a health facility, whereas those with medical complications need such admissions. Children managed at specialized units located at health facilities also require follow up services at their households after discharge in order to maintain a continuum of care and support and to prevent relapse $[19,20]$. The eastern Indian state of Bihar has generated encouraging results through community based intervention in this regard [21]. The current investigation, by highlighting a severe state of under-nutrition in Sundarbans, thus underscores the need for establishing outreach activities paired with facility based intervention. Given the state of wasting among children in the study area indicating both acute and chronic malnutrition, improvement in basic food supply as well as supplementary feeding is warranted [12]. Immunization program for children in the Sundarbans also need to be beefed up as 'full immunization' coverage was estimated in our study population to be $78 \%$. 
Table 2 Association risk factors with anemia in non-pregnant women

\begin{tabular}{|c|c|c|c|c|}
\hline Exposure variables & $\begin{array}{l}\mathrm{Hb}>=120 \\
n=392(\%)\end{array}$ & $\begin{array}{l}\mathrm{Hb}<120 \\
n=698(\%)\end{array}$ & $\mathrm{OR}(95 \% \mathrm{Cl}$ of $\mathrm{OR})$ & $p$-value \\
\hline Durbachati + Ramganga + Gopalnagar (villages) & $117(29)$ & $286(71)$ & $1.66(1.22-2.26)$ & 0.001 \\
\hline Daskhinraypur (village) & $143(40)$ & $218(60)$ & $0.03(0.76-1.40)$ & 0.814 \\
\hline Sreenarayanpur Purnachandrapur (village) & $132(41)$ & $194(59)$ & Reference & - \\
\hline Muslim & $40(43)$ & $54(57)$ & $0.73(0.48-1.13)$ & 0.165 \\
\hline Hindu & $352(35)$ & $644(65)$ & Reference & - \\
\hline Never attended school & $78(30)$ & $18070)$ & $1.39(1.03-1.88)$ & 0.029 \\
\hline Ever attended school & $314(38)$ & $518(62)$ & Reference & - \\
\hline Number of children $>2$ & $120(30)$ & $287(70)$ & $1.58(1.21-2.05)$ & 0.001 \\
\hline Number of children $\leq 2$ & $272(40)$ & $411(60)$ & Reference & - \\
\hline Women not involved in income generation activities & $371(36)$ & $657(64)$ & $0.91(0.53-1.56)$ & 0.721 \\
\hline Women involved in income generation activities & $21(34)$ & $41(66)$ & Reference & - \\
\hline Age $>34$ years & $78(27)$ & $210(73)$ & $1.87(1.11-3.15)$ & 0.083 \\
\hline$>29 \& \leq 34$ years & $59(34)$ & $113(66)$ & $1.33(0.76-2.31)$ & 0.180 \\
\hline$>24 \& \leq 29$ years & $87(39)$ & $134(61)$ & $1.07(0.63-1.81)$ & 0.623 \\
\hline$>19 \& \leq 24$ years & $136(41)$ & $195(59)$ & $0.99(0.60-1.64)$ & 0.992 \\
\hline$\leq 19$ years & $32(41)$ & $46(59)$ & Reference & - \\
\hline $\mathrm{BMI}<18.5 \mathrm{~kg} / \mathrm{m}^{2}$ & $81(30)$ & $185(70)$ & $1.38(1.03-1.86)$ & 0.032 \\
\hline$\geq 18.5 \mathrm{~kg} / \mathrm{m}^{2}$ & $311(38)$ & $513(62)$ & Reference & - \\
\hline Intake polished rice & $5(33)$ & $10(67)$ & $1.12(0.38-3.31)$ & 0.83 \\
\hline Intake per boiled rice & $387(36)$ & $688(64)$ & Reference & - \\
\hline Green vegetables intake frequency - Nil & $1(13)$ & $7(87)$ & $4.46(0.56-38.53)$ & 1.55 \\
\hline $2-4$ days in a month & $86(37)$ & $144(63)$ & $1.11(0.75-1.66)$ & 0.60 \\
\hline 2-3 days in week & $230(35)$ & $434(65)$ & $1.25(0.90-1.75)$ & 0.18 \\
\hline Almost every day & $75(40)$ & $113(60)$ & Reference & - \\
\hline Pulse intake frequency - Nil & $21(35)$ & $39(65)$ & $0.92(0.46-1.88)$ & 0.83 \\
\hline $2-4$ days in a month & $148(37)$ & $252(63)$ & $0.85(0.51-1.39)$ & 0.52 \\
\hline 2-3 days in week & $195(36)$ & $351(64)$ & $0.90(0.55-1.46)$ & 0.67 \\
\hline Almost every day & $28(33)$ & $56(67)$ & - & - \\
\hline Lemon intake frequency with meal- Nil & $207(36)$ & $375(64)$ & $0.74(0.30-1.81)$ & 0.51 \\
\hline $2-4$ days in a month & $152(39)$ & $238(61)$ & $0.64(0.26-1.59)$ & 0.34 \\
\hline 2-3 days in week & $25(27)$ & $68(73)$ & $1.12(0.41-3.02)$ & 0.82 \\
\hline Almost every day & $8(32)$ & $17(68)$ & Reference & - \\
\hline Egg intake frequency - Nil & $28(29)$ & $70(71)$ & $1.42(0.51-4.02)$ & 0.49 \\
\hline $2-4$ days in a month & $287(36)$ & $504(64)$ & $1.02(0.39-2.63)$ & 0.96 \\
\hline 2-3 days in week & $70(38)$ & $112(62)$ & $0.94(0.35-2.50)$ & 0.90 \\
\hline Almost every day & $7(37)$ & $12(63)$ & Reference & - \\
\hline Fish intake frequency - Nil & $2(33)$ & $4(67)$ & $1.20(0.21-6.62)$ & 0.83 \\
\hline $2-4$ days in a month & $61(35)$ & $112(65)$ & $1.10(0.76-1.58)$ & 0.59 \\
\hline 2-3 days in week & $159(35)$ & $299(65)$ & $1.13(0.86-1.48)$ & 0.38 \\
\hline Almost every day & $170(38)$ & $283(62)$ & Reference & - \\
\hline Chicken intake frequency - Nil & $22(34)$ & $42(66)$ & $1.10(0.18-6.50)$ & 0.91 \\
\hline $2-4$ days in a month & $361(36)$ & $461(64)$ & $0.88(0.16-4.85)$ & 0.88 \\
\hline 2-3 days in week & $8(42)$ & $11(58)$ & $0.61(0.90-4.13)$ & 0.61 \\
\hline
\end{tabular}


Table 2 Association risk factors with anemia in non-pregnant women (Continued)

\begin{tabular}{|c|c|c|c|c|}
\hline Almost every day & $1(20)$ & $4(80)$ & Reference & - \\
\hline Animal meat (other than chicken) intake frequency - Nil & $296(35)$ & $556(65)$ & $0.93(0.17-5.15)$ & 0.94 \\
\hline 2-4 days in a month & $93(40)$ & $137(60)$ & $0.73(0.13-4.10)$ & 0.72 \\
\hline 2-3 days in week & $1(50)$ & $1(50)$ & $0.50(0.50-12.89)$ & 0.67 \\
\hline Almost every day & $2(33)$ & $4(67)$ & Reference & - \\
\hline Milk intake frequency - Nil & $66(34)$ & $126(66)$ & $0.88(0.58-1.32)$ & 0.53 \\
\hline $2-4$ days in a month & $217(37)$ & $361(63)$ & $0.78(0.56-1.08)$ & 0.13 \\
\hline $2-3$ days in week & $35(40)$ & $53(60)$ & $0.70(0.42-1.17)$ & 0.18 \\
\hline Almost every day & $74(32)$ & $158(68)$ & Reference & - \\
\hline Fruits intake frequency - Nil & $68(38)$ & $109(62)$ & $0.49(0.18-1.28)$ & 0.14 \\
\hline 2-4 days in a month & $276(36)$ & $495(64)$ & $0.53(0.21-1.34)$ & 0.18 \\
\hline 2-3 days in week & $42(36)$ & $74(64)$ & $0.53(0.20-1.43)$ & 0.21 \\
\hline Almost every day & $6(23)$ & $20(77)$ & Reference & - \\
\hline Germinated gram intake frequency - Nil & $312(36)$ & $546(64)$ & $0.41(0.15-1.11)$ & 0.08 \\
\hline $2-4$ days in a month & $54(39)$ & $85(61)$ & $0.37(0.13-1.06)$ & 0.06 \\
\hline 2-3 days in week & $21(31)$ & $46(69)$ & $0.49(0.16-1.49)$ & 0.21 \\
\hline Almost every day & $5(19)$ & $21(81)$ & Reference & - \\
\hline Drinking water storage in wide mouth container & $291(36)$ & $524(64)$ & $0.95(0.72-1.27)$ & 0.95 \\
\hline Drinking water storage in narrow mouth container & $101(37)$ & $174(63)$ & Reference & - \\
\hline $\begin{array}{l}\text { Draw drinking water by dipping a pot in water } \\
\text { storage vessels }\end{array}$ & $9(53)$ & $8(47)$ & $0.49(0.18-1.28)$ & 0.14 \\
\hline $\begin{array}{l}\text { Draw drinking water by pouring water from } \\
\text { storage vessels }\end{array}$ & $383(36)$ & $690(64)$ & Reference & - \\
\hline Pond/Well/ other water used for washing utensils & $329(36)$ & $573(63)$ & $0.88(0.63-1.22)$ & 0.44 \\
\hline Tubewell/Piped water used for washing utensils & $63(34)$ & $125(66)$ & Reference & \\
\hline Open air defecation & $208(34)$ & $396(66)$ & $1.16(0.91-1.49)$ & 0.24 \\
\hline Use Sanitary toilet/Pakka toilet & $184(38)$ & $302(62)$ & Reference & - \\
\hline Used water/mud/ash for washing hand after defecation & $155(35)$ & $282(65)$ & $1.037(0.80-1.33)$ & 0.78 \\
\hline Use soap for hand wash after defecation & $237(36)$ & $416(64)$ & Reference & - \\
\hline Does not use any contraceptive method for family planning & $93(30)$ & $220(70)$ & $2.02(1.50-2.78)$ & $<0.001$ \\
\hline Contraceptive method apart from Oral pills & $93(28)$ & $240(72)$ & $2.23(1.64-3.02)$ & $<0.001$ \\
\hline Oral pills contraceptive method used for family planning & $206(46)$ & $238(54)$ & Reference & - \\
\hline
\end{tabular}

Worth noting in this context is a sub-study among under-five children we conducted in Ramganga village where 89 diarrhoeic children were contrasted with 105 children not experiencing such episodes. The study showed that children on exclusive breast feeding for less than six months had greater chance of having diarrhoea compared to their counterparts who were breast-fed for longer periods; similarly those who had food from 'anganwadi' centre under integrated child development scheme suffered less [22] from diarrhoea compared to those who did not attend such centres.

Inappropriate child feeding practices were reported by women during the current study. While $90 \%$ of the mothers fed newborns with colostrum, and about a fifth followed ritualistic practices such as feeding newborns with anis water, honey water, sugar candy water or even plain water; $20 \%$ had put their children exclusively on breast for less than six months. Our findings corroborated with that of other investigators who recorded poor knowledge, attitude as well as practices of mothers as regards to child feeding in the Patharpratima block of the Sundarbans [23]. In addition, our study recorded ritualistic practices based on perception of mothers and highlight the need for developing socio-culturally appropriate behaviour change communication.

Lastly, a fourth of the married women in reproductive age group in the study villages suffered from poor health indicated by lower than normal BMI. Hygienic practices were also at a poor state; $41 \%$ of the women reported using water, mud/ash and not soap to wash hands after 
Table 3 Factors independently associated with anaemia in non-pregnant women

\begin{tabular}{|c|c|c|}
\hline Exposure variables & AOR (95\% Cl of AOR) & $p$-value \\
\hline Durbachati + Ramganga + Gopalnagar (villages) & $1.42(1.01-2.01)$ & 0.042 \\
\hline Daskhinraypur (village) & $1.04(0.75-1.43)$ & 0.791 \\
\hline Sreenarayanpur Purnachandrapur (village) & Reference & - \\
\hline Age $>34$ years & $1.33(0.75-2.35)$ & 0.318 \\
\hline$>29 \& \leq 34$ years & $1.12(0.63-2.02)$ & 0.683 \\
\hline$>24 \& \leq 29$ years & $1.05(0.61-1.83)$ & 0.837 \\
\hline$>19 \& \leq 24$ years & $1.03(0.61-1.74)$ & 0.896 \\
\hline$\leq 19$ years & Reference & - \\
\hline Never attended school & $1.15(0.83-1.60)$ & 0.381 \\
\hline Ever attended school & Reference & - \\
\hline Number of children $>2$ & $1.23(0.92-1.65)$ & 0.160 \\
\hline Number of children $\leq 2$ & Reference & - \\
\hline $\mathrm{BMI}<18.5 \mathrm{~kg} / \mathrm{m}^{2}$ & $1.39(1.02-1.89)$ & 0.036 \\
\hline$\geq 18.5 \mathrm{~kg} / \mathrm{m}^{2}$ & Reference & - \\
\hline Germinated gram intake frequency - Nil & $0.47(0.17-1.28)$ & 0.142 \\
\hline $2-4$ days in a month & $0.43(0.15-1.25)$ & 0.125 \\
\hline 2-3 days in week & $0.56(0.18-1.74)$ & 0.322 \\
\hline Almost every day & Reference & - \\
\hline Does not use any contraceptive method for family planning & $1.86(1.36-2.54)$ & $<0.001$ \\
\hline Contraceptive method apart from Oral pills & $1.84(1.32-2.56)$ & $<0.001$ \\
\hline Oral pills contraceptive method used for family planning & Reference & - \\
\hline
\end{tabular}

defecation. Village-disaggregated data revealed that the prevalence of anaemia in women in all the villages was of concern. Factors independently associated with anaemia in women were non-adoption of family planning, non-use of oral contraceptive pill as a family planning method and residence at DC-RG-GN. As usage of hormonal oral contraceptive pills (OCP) by women is known to improve the level of iron reserve in women as indicated by increased haemoglobin as well as ferritin level [24] and also by reducing menstrual blood loss [25], it was necessary to inquire about OCP and non-OCP based family planning methods in detail. However, family planning methods followed by women would not suffice as sole explanatory factor behind prevalence of anaemia in women of reproductive age group in the study area as 'number of children of women' did not have statistically significant association with anaemia. Detailed dietary habits, available and absorbable iron present in the food items consumed, sanitary practices (keeping in mind the link between open defecation and soil-transmitted helminths) and chronic morbidities experienced by women would also need to be researched in-depth.

It is noteworthy that $78 \%$ women did not report consumption of any red meat. While potential intervention around such observations and findings on the link between family planning method and anaemia could be conceived, it is important to note that a review of interventions from Indian states of Uttar Pradesh, Maharashtra, Gujarat, Rajasthan, Jharkhand, West Bengal and Bangalore has highlighted evidence gaps existing in the country regarding management of iron deficiency anaemia [26]. Implementing effective intervention to reduce anaemia in women in a setting like Sundarbans would therefore require innovation. At a smaller scale though, dissemination of current situation assessment findings to local level stakeholders including district magistrates, civil society organizations, local village administration (panchayat) and participating women fostered positive health seeking behaviour [27]. However, the population-level challenge still remains as the recently released preliminary findings of NFHS-Round 4 (2015-2016) for the district of south 24-Parganas reveals that $20 \%$ of the women in 15-49 years age group is recorded to have BMI lower than normal and $69 \%$ of non-pregnant women in the same age group has anaemia [28].

\section{Conclusion}

Despite several limitations such as cross-sectional nature of our investigation necessitating simultaneous collection of information on outcome (such as anaemia in women) 
as well as key risk factors and lack of in-depth investigation about causes of anaemia in women, the present situation assessment has unearthed serious public health situation prevailing in the Sundarbans area of West Bengal, India. Limited availability of resources also did not allow in-depth exploration of dietary assessments of the study population. However, two key parameters under-nutrition in children and anaemia in women have served important role in assessing the health of the study population. While, in view of the existing 'critical' state of under-nutrition, securing food and nutrition for the entire underserved villages has emerged as an immediate need, the situation of anaemia in women calls for innovative intervention development. Active engagement of local level stakeholders, community and health authorities would be critical in all such endeavours.

\section{Abbreviations}

AOR: Adjusted odds ratio; BCG: Bacillus of Calmette-Guerin; BMI: Body Mass Index; Cl: Confidence interval; DC-RG-GN: Durbachati-Ramganga-Gopalnagar (villages); DPT: Diphtheria-Pertussis-Tetanus; DR: Dakshinraypur (village); HfA: Height for age; ICMR: Indian council of medical research; MUAC: Midupper arm circumference; NFHS: National family health survey; NICED: National Institute of Cholera \& Enteric Diseases; OR: Odds Ratio; SAM: Severe acute malnutrition; SC: Save the children; SD: Standard deviation; SN: Sreenarayanpur-purnachandrapur; SSDC: Sundarbans social development centre; WfA: Weight for age; WfH: Weight for height; WHO: World Health Organization

\section{Acknowledgements}

Not applicable.

\section{Funding}

The study was supported entirely by extramural financial assistance received by NICED from Save the Children (SC), West Bengal Office who in turn was supported by Sweden. The decision makers at SC office about funding did not have any role in the design, collection, analysis, and interpretation of data and in writing the manuscript.

\section{Availability of data and materials}

The datasets generated or analysed during the current study are not publicly available due to unique geographical vulnerability and sensitivity attached to the study location situated at the bordering area between India and Bangladesh but are available from the corresponding author on reasonable request.

\section{Authors' contributions}

While SP, CP and GP were responsible for study design, SP, GP, SoP and JH contributed in study tool development and SP, CP and SoP were involved in supervising implementation of the current assessment. SP, SoP \& JH were involved in data cleaning and analyses. All the authors provided critical inputs in various stages of study execution and read and approved the final version of the article for submission.

\section{Authors' information}

Not applicable.

\section{Competing interests}

While SaP conducted the assessment on behalf of NICED, SOP and JH were staff of the assessment Project. During the present assessment CS, served as a staff of Save the Children (SC, Bal Rakshak Bharat), West Bengal State Office that extended financial support under extramural assistance to NICED (ICMR) for conducting the study and GP belonged to the collaborating civil society organization SSDC that received grants from SC for intervention in localities in the study district.
Consent for publication

Not applicable.

\section{Ethics approval and consent to participate}

The present study obtained approval from the "Institutional Ethics Committee" of the National Institute of Cholera \& Enteric Diseases (Indian Council of Medical Research), Registration No. ECR/416/Inst.MB/2013 (Under DCGI) and informed consent was obtained from the each of the study participants (when adult) and from the legal guardians of the minors (under-5-children) prior to recruitment.

\section{Author details}

${ }^{1}$ National Institute of Cholera \& Enteric Diseases (NICED, Indian Council of Medical Research), P-33 CIT Road, Scheme-XM, Beliaghata, Kolkata PIN 700010, West Bengal, India. '2Save the Children (SC, Bal Rakshak Bharat), West Bengal State Office, 41B/5, Gariahat Road (South), Kolkata 700031, India. ${ }^{3}$ Sundarban Social Devlopment Centre (SSDC), South 24 Parganas, Lakshmikantapur, West Bengal, India. ${ }^{4}$ SSDC-NICED-SC Collaborative Project, P-33 CIT Road, Scheme-XM, Beliaghata, Kolkata 700010, India.

Received: 3 June 2016 Accepted: 29 October 2016

Published online: 08 November 2016

\section{References}

1. Bhutta ZA, Gupta I, De'Silva H, Manandhar D, Awasthi S, Moazzem Hossain SM, et al. Maternal and child health: is south Asia ready for change. BMJ. 2004;328:816-9.

2. Jha P, Laxminarayan R. Choosing Health: an entitlement for all Indians. Toronto: Centre for Global Health Research; 2009. p. 12-13.

3. Subramanian SV, Ackerson LK, Smith GD. Parental BMI and Childhood under-nutrition in India: an assessment of intrauterine influence. Pediatrics. 2010;126:e663-71. doi:10.1542/peds.2010-0222.

4. Singh OP. Long-term trends in the frequency of severe cyclones of Bay of Bengal: observations and simulations. Mausam. 2007;58:59-66.

5. Centre for Science and Environment. Living with changing climate: Impact, vulnerability and adaptation challenges in Indian Sundarbans. (supported by) DanChurch Aid, Church of Sweden, Swedish International Development Agency (SIDA) and Evangelischer Entwicklungsdienst e.V (EED) 2012.

6. Panda S, Pati KK, Bhattacharya MK, Koley H, Pahari S, Nair GB. Rapid situation $\&$ response assessment of diarrhoea outbreak in a coastal district following tropical cyclone AlLA in India. Indian J Med Res. 2011;13:395-400.

7. Bharati S, Chakrabarty S, Som S, Pal M, Bharati P. Socio-economic determinants of underweight children in West Bengal, India. Asian Pac J Trop Med. 2010;3:322-7.

8. Sengupta B and Chakrabarti S. Study of anaemia among rural women of some districts of West Bengal with a view to use biotechnological methods. (Final Report DBT MB sanction letter No.: 61/ 1(5)-BT Estt /RD-3/08 dt 05.02.2008) Ramakrishna Mission Seva Pratisthan Vivekananda Institute of Medical Sciences.

9. Lwanga SK, Lemeshaw S. Sample size determination in health studies: a practical manual. Geneva: World Health Organization; 1991. p. 2-3.

10. IIPS and Macro International. National Family Health Survey (NFHS-2), 1998-99: India. Mumbai: International Institute of Population Sciences; 2000.

11. World Health Organization \& UNICEF. WHO child growth standards and the identification of severe acute malnutrition in infants and children - a joint statement by the World Health Organization and the United Nations Children's Fund. 2009.

12. World Health Organization Regional Office for the Eastern Mediterranean. Field guide on rapid nutritional assessment in emergencies. 1995.

13. WHO expert consultation. Appropriate body-mass index for Asian populations and its implications for policy and intervention strategies. Lancet. 2004;363:157-63.

14. World Health Organization (WHO) \& Centre for Disease Control (CDC) Atlanta. In: De BB, McLean E, Egli I, Cogswell M, editors. Worldwide prevalence of anemia 1993-2005: WHO global database on anemia. 2008

15. G Mazumdar P, Kanjilal B, Barman D, Mandal A. Revisiting the Role of Geographical Accessibility in Women's Access to Healthcare. Rajasthan: Institute of Health Management Research; 2009.

16. Dipanwita D. Spatial inequality in healthcare infrastructure in Sundarban, West Bengal, India. Int Res J Soc Sci. 2014;3:15-22.

17. International Institute for Population Sciences (IIPS) and Macro International. National Family Health Survey (NFHS-3), 2005-2006. Mumbai (India): IIPS; 2007. 
18. UNICEF. Tracking progress on child and maternal nutrition: a survival and development priority. New York: UNICEF; 2009.

19. Collins S, Sadler K, Dent N, Khara T, Guerrero S, Myatt M, et al. Key issues in the success of community-based management of severe malnutrition. Food Nutr Bull. 2006;27:S49-82.

20. National Rural Health Mission, Ministry of Health and Family Welfare, Government of India. Operational guidelines on facility based management of children with severe acute malnutrition. 2011.

21. Burza S, Mahajan R, Marino E, Sunyoto T, Shandilya C, Tabrez M, et al. Community-based management of severe acute malnutrition in India: new evidence from Bihar. Am J Clin Nutr. 2015;101:847-59.

22. SSDC-NICED-Save the Children. Health status of women and children in Sundarbans. 2014. p. 10-1.

23. Institute of Health Management Research (IIHMR). Combating Malnutrition in Children in Disaster Prone Patharpratima Block of Sundarbans, West Bengal (India), Baseline Study Report (submitted to Tdh Foundation). January 2012

24. Task Force for Epidemiological Research on Reproductive Health, United Nations Development Programme/United Nations Population Fund/World Health Organization/World Bank Special Programme of Research, Development and Research Training in Human Reproduction, World Health Organization, Geneva, Switzerland. Effects of contraceptives on hemoglobin and ferritin. Contraception. 1998:58:261-73.

25. Carey M, Allen RH. Non-contraceptive uses and benefits of combined oral contraception. Obstetrician Gynaecologist. 2012;14:223-8. doi:10.1111/j-17444667.2012.00126.x

26. USAID \& Vistaar. Community-level interventions to prevent and treat anemia: a review of evidence from India. Evidence Review Series 3; March 2008.

27. Save the Children. Environmental Health: stories from the Sundarbans (supported by Sweden). 2013. p. 2-3.

28. International Institute for Population Sciences (IIPS) and Macro International. National Family Health Survey-4: District Fact Sheet South 24 Parganas West Bengal 2015-2016. (Assistance from Ministry of Health \& Family Welfare; Government of India, USAID, UKaid, Bill \& Melinda Gates Foundation, UNICEF, UNFPA, McArthur Foundation). 2016.

\section{Submit your next manuscript to BioMed Central and we will help you at every step:}

- We accept pre-submission inquiries

- Our selector tool helps you to find the most relevant journal

- We provide round the clock customer support

- Convenient online submission

- Thorough peer review

- Inclusion in PubMed and all major indexing services

- Maximum visibility for your research

Submit your manuscript at www.biomedcentral.com/submit 